\title{
Embryonal Origin of Metanephric Adenoma and its Differential Diagnosis
}

\author{
DONAT PETER SARLOS ${ }^{1}$, DANIEL BANYAI $^{1}$, LEHEL PETERFI $^{1}$, ARPAD SZANTO ${ }^{1}$ and GYULA KOVACS ${ }^{1,2}$ \\ ${ }^{1}$ Department of Urology, Medical School, University of Pecs, Pecs, Hungary; \\ ${ }^{2}$ Medical Faculty, Ruprecht-Karls-University, Heidelberg, Germany
}

\begin{abstract}
Background/Aim: The association of Wilms' tumor $(W T)$, papillary renal cell tumor (PRCT) and mucinous tubular and spindle cell carcinoma (MTSCC) with embryonal rests has already been documented, but the cellular origin of metanephric adenoma (MA) is not yet known. The aim of this study was to understand their developmental evolution and find diagnostic markers. Materials and Methods: CD57, KRT7, AMACR, SCEL, WTI and CDH17 expression was analysed by immunohistochemistry in the four types of tumors and the associated pre-neoplastic lesions. Results: Immunohistochemistry was able to differentiate WT, MA, MTSCC and PRCT. A phenotypic correlation between MA and perilobar nephrogenic rest associated with WT was identified. Conclusion: Perilobar nephrogenic rest and MA arise from differentiation arrested cells of the proximal domain of the S-shape body. We propose that WTI, MA, MTSCC and PRCT derive from different forms of maturation arrested embryonal rests.
\end{abstract}

Metanephric adenoma (MA) is an epithelial tumor of the kidney composed of small, uniform, embryonal-looking cells, which are frequently seen in nephrogenic rests (NR) associated with Wilms tumor (WT) (1). Initially it was suggested that MA derives from persistent blastemal cells (2). Following the first description several concepts were published regarding its possible origin. It has been proposed, that the more active malignant WT matures with time into an inactive benign MA (3). Because MA may display a papillary growth pattern and sometimes psammoma bodies, which are characteristic for papillary renal cell tumor (PRCT), it was considered to be a solid variant of PRCT (4).

Correspondence to: Gyula Kovacs, Department of Urology, Medical School, University of Pecs, Munkacsy M. u. 2, H-7621 Pecs, Hungary. Tel: +36 72507334, Fax: +36 72242374, e-mail: g.kovacs@gmx.de; gyula.kovacs@urz.uni-heidelberg.de

Key Words: Metanephric adenoma, embryonal origin, nephrogenic rest, CDH17, immunohistochemistry.
PRCT is composed by solid, tubular and papillary structures and display the whole spectrum of epithelial differentiation, from small blastema-like cells towards more differentiated epithelial cells. Another kidney tumor, mucinous tubular and spindle cell carcinoma (MTSCC) may also contain small cells growing in solid or papillary formations $(5,6)$. Because of the latter growth pattern, it was proposed that MTSCC is a variant of PRCT (7).

The association of WT, MTSCC and PRCT with NR and pre-neoplastic lesion (PNL) has already been documented, but the origin of MA is not yet known $(6,8,9)$. WT, MTSCC and PRCT arise from not fully differentiated cells that may explain their heterogeneous morphology and overlapping phenotype, the latter leading in some cases to differential diagnostic problem. Although the genetic analysis can identify WT, MA, MTSCC and PRCT unequivocally, it does not give information about their cellular origin $(5,6,10-12)$. Several antibodies have been proposed to identify WT, MA, MTSCC and PRCT, even those with an overlapping phenotype. It was reported that solid growing PRCT, a mimicry of MA, is positive for KRT7 and AMACR, epithelial predominant WT for WT1 and MA for WT1 and CD57 antibodies (13-15). Recently, CDH17 has been added to this panel as an MA-specific marker (16).

The aim of this study was to establish the marker profile of diagnostic importance for the abovementioned tumors by using immunohistochemistry with WT1, CD57, AMACR, KRT7, SCEL and CDH17 antibodies. Moreover, the associated precursor lesions were analyzed to get an insight into their cellular origin and natural history.

\section{Materials and Methods}

Tissue samples. Twelve tri- or biphasic WT including 4 with MAlike areas, and 3 WT with blastemal predominant histological pattern were included. Ten MAs, 9 MTSCCs and 76 papillary RCTs including 18 cases with solid or solid-tubular growth pattern of small "blue cells" were also subjected to immunohistochemistry. In addition, 9 PLNR, 4 and 10 PNL associated with WT, MTSCC and PRCC, respectively, were examined. Original paraffin blocks of 3 foetal and 3 adult kidneys, WT, MA, MTSCC, PLNR and PNL as 
well as a tissue microarray (TMA) containing multiple core biopsies of 76 PRCT were used for this study. TMA was constructed by one of the authors (GK) as described earlier (9).

Immunohistochemistry. For IHC staining $4 \mu \mathrm{m}$ sections placed onto FLEX IHC microscope slides (DAKO, Glostrup, Denmark) were dewaxed in xylene and rehydrated in graded ethanol. Antigen retrieval was performed by boiling the slides in $10 \mu \mathrm{M}$ sodium citrate buffer, pH 6.0 in 2100-Retriever (Pick-Cell Laboratories, Amsterdam, The Netherlands). Endogenous peroxidase activity and nonspecific staining were blocked by incubation with $3 \%$ hydrogen peroxide containing $1 \%$ normal horse serum for $10 \mathrm{~min}$ at room temperature. Slides were then incubated overnight at $4^{\circ} \mathrm{C}$ in moist chamber with rabbit polyclonal anti- CDH17 antibody (NBP131225, Novus Biologicals, Littleton, CO, USA) at the dilution of 1:500 and anti SCEL antibody (HPA040154, Sigma Aldrich, Budapest, Hungary) at the dilution of 1:250. HRP conjugated antirabbit secondary antibody (MACH4 Universal HRP-Polymer, Biocare Medical, Concord, CA, USA) was applied for 30 minutes and colour was developed using DAB substrate (DAKO). Tissue sections were counterstained with Mayer's hematoxylin (DAKO) and cover-slipped with Pertex (Medite GmbH, Burgdorf, Germany). In negative controls, the primary antibody was omitted.

Tissue sections were also stained with mouse monoclonal antiKRT7 antibody (OV-TL, M7018, DAKO) at the dilution 1:3000, rabbit monoclonal anti-p504S/AMACR antibody (13H4, RM-9130-A, Thermo-Scientific) at 1:150 dilution, mouse monoclonal anti CD57 antibody (NCL-NK1, Leica Novocastra) at 1:100 dilution, mouse monoclonal anti-WT1 antibody (6F-H2, M3561, DAKO) at dilution 1:100, after antigen retrieval at $\mathrm{pH} 6$ and $\mathrm{pH} 9$, respectively. The IHC was processed in a BOND-MAX Automated IHC/ISH Stainer (Leica Biosystems) and the reaction was visualized by DAB (DAKO). The results were evaluated by scoring as negative or positive, the latter classified according to the percentage of positive cells.

\section{Results and Discussion}

Differentiation between WT, MA, MTSCC and PRCT and their precursor lesion by immunohistochemistry. The immune profile of tumors which are considered to be derived from embryonal remnants $(2,6,8,9)$ is described. The result of immunohistochemistry of tumors as well as the associated precursor lesions are summarized in Table I. The B3GAT1 gene product $\mathrm{CD} 57$ has been proposed to be a reliable marker for MA $(13,15)$. In our study not only MA but also WT, MTSCC and PRCT showed a strong reaction with CD57 antibody, albeit in different percentage of tumor cells. The epithelial components of WTs with MA-like structures have also displayed positive staining for CD57. Our findings confirm the results of two other studies reporting CD57 positivity in MA, WT and PRCT as well $(4,17)$. The positive CD57 staining in all types of tumor and their precursor lesions exclude CD57 as marker for MA and for its possible cellular origin.

WT1, KRT7 and AMACR antibodies differentiated between two groups of tumors and their precursor lesions (Table I). The WT1 antibody showed a positive immune
Table I. Immunohistochemistry of WT, MA, MTSCC, PRCT and precursor lesions.

\begin{tabular}{|c|c|c|c|c|c|c|c|}
\hline \multirow[t]{2}{*}{ Antibodies } & \multicolumn{2}{|c|}{ WT } & \multirow[t]{2}{*}{ MA } & \multicolumn{2}{|c|}{ MTSCC } & \multicolumn{2}{|c|}{ PRCT } \\
\hline & PLNR & $\mathrm{T}$ & & PNL & $\mathrm{T}$ & PNL & $\mathrm{T}$ \\
\hline CD57 & $9 / 9$ & $15 / 15$ & $10 / 10$ & $4 / 4$ & $7 / 9$ & $10 / 10$ & $56 / 76$ \\
\hline WT-1 & $9 / 9$ & $12 / 15$ & $10 / 10$ & $0 / 4$ & $0 / 9$ & $0 / 10$ & $0 / 76$ \\
\hline CDH17 & $9 / 9$ & $0 / 15$ & $9 / 10$ & $0 / 4$ & $0 / 9$ & $0 / 10$ & $2 / 76$ \\
\hline KRT7 & $0 / 9$ & $0 / 15$ & $0 / 10$ & $3 / 4$ & $6 / 9$ & $7 / 10$ & $57 / 76$ \\
\hline AMACR & $0 / 9$ & $0 / 15$ & $0 / 10$ & $2 / 4$ & $8 / 9$ & $7 / 10$ & $74 / 76$ \\
\hline SCEL & $0 / 9$ & $0 / 15$ & $0 / 10$ & $0 / 4$ & $0 / 9$ & $7 / 10$ & $57 / 76$ \\
\hline
\end{tabular}

WT: Wilms tumor; PLNR: perilobar nephrogenic rest; T: tumor; MA: metanephric adenoma; MTSCC: mucinous tubular and spindle cell carcinoma; PNL: pre-neoplastic lesion; PRCT: papillary renal cell tumor.

reaction in 12 of $15 \mathrm{WT}$, in all perilobar nephrogenic rests (PLNR) and MA. However, none of the 9 MTSCC, 76 PRCC and associated pre-neoplastic lesions (PNL) displayed nuclear staining with WT1. MTSCC and PRCT as well as their PNL were all positive for KRT7 and AMACR. Our data are in line with previous observations showing that both PRCT and MTSCC are positive for KRT7 and AMACR whereas epithelial predominant WT and MA for WT1 (13, 15). Our study revealed that SCEL immunohistochemistry can differentiate between MTSCC and PRCT and associated PNL. Within the first group of tumors CDH17 antibody differentiated between WT and MA. All but one MA but none of the 15 WT expressed the CDH17 protein. Surprisingly, each of the 9 PLNR associated with WT was positive for $\mathrm{CDH} 17$ indicating an overlapping phenotype of MA and PLNR (Table I).

Expression of CDH17 in normal kidney. This unexpected result prompted us to analyse the expression of $\mathrm{CDH} 17$ and also the WT1 in developing kidneys. Foetal kidneys at gestational age of 12 weeks showed a positive staining with CDH17 only in parietal epithelium of Bowman's capsule, but not in the proximal tubules or other structures (Figure 1E). Kidneys of 3-6 months old infants and adults were completely negative. The WT1 was positive in cells of the proximal compartments of the S-shape body, glomerular podocytes and in some parietal cells of Bowman's capsule in kidneys of 12 weeks old foetus (Figure 1F). In infants and adults, a strong nuclear positivity was seen in $50-70 \%$ of podocytes. The expression of $\mathrm{CDH} 17$ in parietal cells of the Bowman capsule was not expected because it is known to be specifically expressed in gastrointestinal tract and tumors arising from the digestive system including hepatocellular carcinoma (18). CDH17 gene encodes a cadherin-like protein with 7 extracellular cadherin domains and a transmembrane 

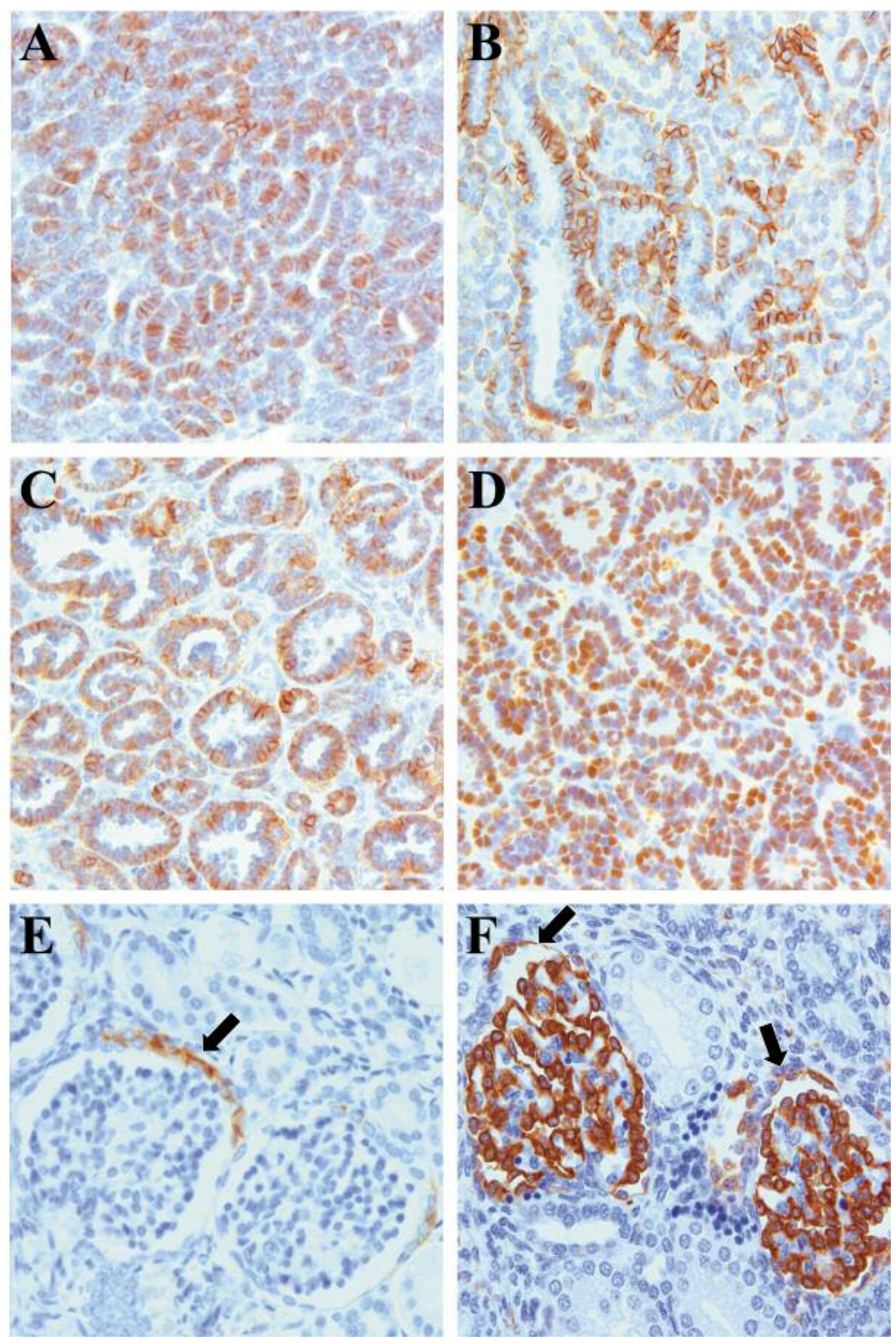

Figure 1. Immunohistochemistry of CDH17 and WT1. (A) Positive staining with anti-CDH17 antibody in a tubular growing metanephric adenoma. (B) Strong CDH17 immune-reaction in a MA with papillary structures. (C) Expression of CDH17 antibody in tubular growing perilobar nephrogenic rest and (D) WT1-positive staining in a perilobar nephrogenic rests both associated with Wilms tumor. (E) Positive immunoreaction with antiCDH17 antibody in the parietal epithelium of the Bowman capsule in foetal kidney (arrow). (F) Strong positive staining with the WT1 antibody in the podocytes and parietal cells of the Bowman capsule in a foetal kidney (arrows).

region but has no conserved cytoplasmic domain. It has a structural similarity to CDH16, a kidney-specific cadherin, but no expression of $\mathrm{CDH} 17$ was seen in adult kidneys.

Metanephric adenoma arises from perilobar nephrogenic rest. Termination of nephrogenesis and differentiation of specialized cell types along the nephron is a well-coordinated molecular process controlled by several genes (19). By the S-shaped body stage, expression of WT1 is seen in proximal domain, where there is a distinct separation of cellular morphology between those cells fated to be podocytes and those forming parietal epithelial cells of Bowman's capsule (20). The impaired differentiation of cells of the proximal domain may lead to the development of PL-NR, expressing WT1 and CDH17 (Figure 1C and D), and subsequently to the development of MA. The observation that $\mathrm{CDH} 17$ is expressed in PL-NR and MA and in parietal cells of the Bowman's capsule exclusively in foetal kidneys strengthens 


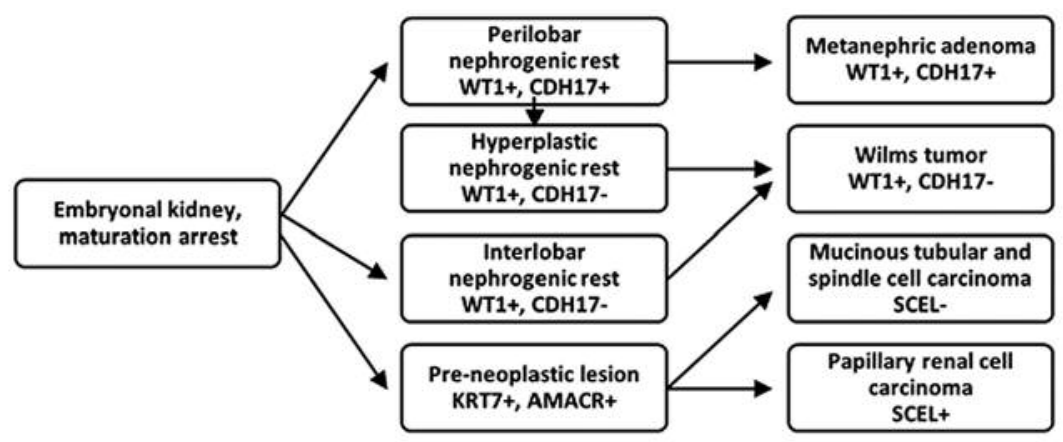

Figure 2. Proposed developmental sequences of WT, MA, MTSCC and PRCT due to embryonal differentiation arrest and results of immunohistochemistry supporting the hypothesis.

this suggestion (Figure 1A-C, E). The development of diffuse tubular adenomas replacing both kidneys after a first trimester suicide attempt with aspirin also suggests that diffuse maturation arrest may lead to this alteration (21). "Embryonal hyperplasia of the Bowman capsular epithelium" (EHBCE) was observed in an infant with germ line WT1 mutations having progressive kidney failure (22). Association of EHBCE with MA has also been reported (23). Hughson et al. observed EHBCE in end stage kidney, which developed during remodelling of kidney structures in adults and therefore, cannot be originated from impaired cellular differentiation during nephron development (24). The presence of CD24- and CD133-positive cells in the epithelium of Bowman's capsule suggests that these cells retain their plasticity throughout life and they may be the source of regeneration of podocytes and also of EHBCE in end stage kidneys of adults $(25,26)$.

\section{Conclusion}

In this study, immunohistochemistry revealed that different types of embryonal rest may occur. WT is known to be associated with IL-NR and PL-NR. IL-NR is arising due to differentiation arrest at earliest stage of nephron development and has potential to develop different mesenchymal and epithelial structures such as blastemal, stromal and epithelial cells of distinct cellular lineages characteristic for tri- or biphasic WT (8). The PL-NR, however, corresponds to impaired differentiation of primitive epithelial cells at a narrow window of epithelial differentiation, shows a slow but continuous growth and may evolve to MA. Within a PLNR, hyperplastic lesions (HP-NR) may develop sometimes leading to epithelial form of WT (8). The pre-neoplastic lesions (PNL) associated with MTSCC and PRCT arise after completing the mesenchymal-to-epithelial transition and therefore their potential is limited exclusively to development of epithelial lesions (Figure 2).
One of the novel findings of our study is the documentation that, in spite of earlier suggestion (4), MA and PRCT are distinct entities derived from different precursors at different developmental stages of embryonal kidney. Another novel finding is the demonstration of a phenotypic correlation between PL-NR and MA suggesting their common origin from differentiation arrested cells of the proximal domain of S-shape body fated to form the parietal cells of the Bowman's capsule. The finding that all WT including those with MA-like structures were negative for $\mathrm{CDH} 17$ antibody staining excludes the possibility that MA is the hyper differentiated benign end of WT spectrum. The specificity of CDH17 staining in the diagnosis of MA was confirmed and was shown that WT1, CDH17, AMACR, KRT7 and SCEL immunohistochemistry can differentiate WT, MA, MTSCC and PRCC. We propose that WT1, MA, MTSCC and PRCC derive from different types of embryonal rest.

\section{Conflicts of Interest}

The Authors have no conflicts of interest to declare.

\section{Acknowledgements}

This work was supported by a grant of PTE-AOK KA-2016-01. The Authors would like to thank Zsuzsanna Halas for preparing the slides and also Judit Szilagyine for helping in the immunohistochemistry. The collection and use of all tissue samples for this study was approved by the Ethics Committee of the University of Pecs, Hungary (No. 5343/2014).

\section{References}

1 Moch H, Humphrey PA, Ulbright TM and Reuter VE (eds.): WHO Classification of tumours of the urinary system and male genital organs (4th edition). IARC: Lyon, 2016.

2 Brisigotti M, Cozzutto C, Fabbretti G, Sergi C and Callea F: Metanephric adenoma. Histol Histopathol 7: 689-692, 1992. 
3 Argani P: Metanephric neoplasms: the hyperdifferentiated, benign end of the Wilms tumor spectrum? Clin Lab Med 25: 379-392, 2005.

4 Mantoan Padilha M, Billis A, Alende D, Zhou M and MagiGalluzzi C: Metanephric adenoma and solid variant of papillary renal cell carcinoma: common and distinctive features. Histopathology 62: 941-953, 2013.

5 Rakozy C, Schmahl GE, Bogner S and Storkel S: Low-grade tubular-mucinous renal neoplasms: morphologic, immunohistochemical, and genetic features. Mod Pathol 15: 1162-1171, 2002.

6 Banyai D, Vastag F, Yusenko M, Bugert P and Kovacs G: Embryonal origin of MTSCC of kidney may explain its morphological heterogeneity: Diagnostic impact of genetic analysis. Anticancer Res 37: 1185-1189, 2017.

7 Shen SS, Ro JY and Tamboli P: Mucinous tubular and spindle cell carcinoma of kidney is probably a variant of papillary renal cell carcinoma with spindle cell features. Ann Diagn Pathol 11: 13-21, 2007.

8 Beckwith JB, Kiviat NB and Bonadio J: Nephrogenic rests, nephroblastomatosis and the pathogenesis of Wilms' tumor. Pediatr Pathol 10: 1-36, 1990.

9 Banyai D, Sarlos P, Nagy A and Kovacs G: Recalling Cohnheim's theory: Papillary renal cell tumor as a model of tumorigenesis from impaired embryonal development to malignant tumors in adults. Int J Biol Sci 14: 784-790, 2018.

10 Natrajan R, Williams RD, Hing SN, Mackay A, Reis-Filho JS, Fenwick K, Iravani M, Valgeirsson H, Grigoriadis A, Langford CF, Dovey O, Gregory SG, Weber BL, Ashworth A, Grundy PE, Pritchard-Jones $\mathrm{K}$ and Jones $\mathrm{C}$ : Array $\mathrm{CGH}$ profiling of favourable histology Wilms tumours reveal novel gains and losses associated with relapse. J Pathol 210: 49-58, 2006.

11 Szponar A, Yusenko MV and Kovacs G: High-resolution array CGH of metanephric adenomas: lack of DNA copy number changes. Histopathology 56: 212-216, 2010.

12 Balint I, Szponar A, Jauch A and Kovacs G: Trisomy 7 and 17 marks papillary renal cell tumours irrespectively of variation of the phenotype. J Clin Pathol 62: 892-895, 2009.

13 Reuter VE, Argani P, Zhou M and Delahunt B: Best practices recommendations in the application of immunohistochemistry in the kidney tumors. Report from the International Society of Urologic Pathology Consensus Conference. Am J Surg Pathol 38: e35-e49, 2014.

14 Paner GP, Srigley JR, Radhakrishnan A, Cohen C, Skinnider BF, Tickoo SK, Young AN and Amin MB: Immunohistochemical analysis of mucinous tubular and spindle cell carcinoma and papillary renal cell carcinoma of the kidney: significant immunophenotypic overlap warrants diagnostic caution. Am J Surg Pathol 30: 13-19, 2006.

15 Kinney SN, Eble JN, Hes O, Williamson SR, Grignon DJ, Wang M, Zhang S, Baldrige LA, Martignoni G, Brunelli M, Wang L, Comperat E, Fan R, Montironi R, MacLennan GT and Cheng L: Metanephric adenoma: the utility of immunohistochemical and cytogenetic analysis in differential diagnosis, including solid variant papillary renal cell carcinoma and epithelial-predominant nephroblastoma. Mod Pathol 28: 1236-1248, 2015.
16 Yakirevich E, Magi-Galluzzi C, Grada Z, Lu S, Resnick MB and Mangray S: Cadherin 17 is a sensitive and specific marker for metanephric adenoma. Am J Surg Pathol 39: 479-486, 2015.

17 Muir TE, Cheville JC and Lager DJ: Metanephric adenoma, nephrogenic rests, and Wilms tumour: a histologic and immunophenotypic comparison. Am J Surg Pathol 25: 12901296, 2001

18 Berndorff D, Gessner R, Kreft B, Schnoy N, Lajous-Petter AM, Loch N, Reutter W, Hortsch M and Tauber R: Liver-intestine cadherin: molecular cloning and characterisation of a novel $\mathrm{Ca}(2+)$-dependent cell adhesion molecule expressed in liver and intestine. J Cell Biol 125: 1353-1369, 1994.

19 Li CM, Guo M, Borczuk A, Charles A. Powell CA, Wei M, Thaker HM, Friedman R, Klein $U$ and Tycko B: Gene expression in Wilms" tumor mimics the earliest committed stage in the metanephric mesenchymal-epithelial transition. Am J Pathol 160: 2181-2190, 2002.

20 Takemoto M, He L, Norlin J, Patrakka J, Xiao Z, Petrova T, Bondjers C, Asp J, Wallgard E, Sun Y, Samuelsson T, Mostad P, Lundin S, Miura N, Sado Y, Alitalo K, Quaggin SE, Tryggvason $\mathrm{K}$ and Betsholtz C: Large-scale identification of genes implicated in kidney glomerulus development and function. EMBO J 25: 1160-1174, 2006.

21 Bove KE, Bhathena D, Wyatt RJ, Lucas BA and Holland NH: Diffuse metanephric adenoma after in utero aspirin intoxication. A unique case of progressive renal failure. Arch Pathol Lab Med 103: 187-190, 1979.

22 Fukuzawa R, Eccles MR, Ikeda M and HATA J: Embryonal hyperplasia of Bowman s capsular epithelium in patients with WT1 mutations. Pediatr Nephrol 18: 9-13, 2003.

22 Keshani de Silva V, Tobias V, Kainer G and Beckwith B: Metanephric adenoma with embryonal hyperplasia of Bowman's capsular epithelium: previously unreported association. Pediatr Dev Pathol 3: 472-478, 2000.

24 Hughson MD, McManus JFA and Hennigar GR: Studies on "end-stage" kidneys. II. Embryonal hyperplasia of Bowman s capsular epithelium. Am J Pathol 91: 71-80, 1978.

25 Appel D, Kershaw DB, Smeets B, Yuan G, Fuss A, Frye B, Elger M, Kriz W, Floege $J$ and Moeller MJ: Recruitment of podocytes from glomerular parietal epithelial cells. J Am Soc Nephrol 20: 333-343, 2009.

26 Ronconi E, Sagrinati C, Angelotti ML, Lazzeri E, Mazzinghi B, Ballerini L, Parente E, Becherucci F, Gacci M, Carini M, Maggi E, Serio M, Vannelli GB, Lasagni L, Romagnani S and Romagnani P: Regeneration of glomerular podocytes by human renal progenitors. J Am Soc Nephrol 20: 322-332, 2009.

Received October 27, 2018

Revised November 7, 2018

Accepted November 8, 2018 